\title{
Not so clear after all
}

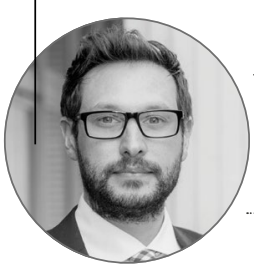

\section{David Westgarth}

Editor, BDJ in Practice

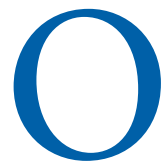

ne of life's many unwritten rules is that no matter how much you're told not to, scratching an itch is wonderful. That instantaneous hit of relief is magical; were it able to be bottled and sold, whoever did so would make millions.

And yet by doing so, it causes problems, kicks the problem down the road, masks the real issue - the underlying cause. After returning home from far flung corners of the globe, my skin would invariably start to peel. I know that sitting in the sun for hours on end - even with factor 50 on - isn't super safe, but boy do I love it. Factor 50 becomes factor 30 , which morphs quickly into 15 as my holiday draws to a conclusion. I call it last-minute cramming, and yes, it does involve lathering on aftersun. Alas, it is to no avail, as I begin to peel and itch like Baloo the Bear scratching his back from The Jungle Book.

In my mind, dentistry is now facing up to its own itch in the form of direct-toconsumer orthodontics. The problem started in 2019, when murmurs of discontent could be heard about the practise. Was it safe? Was it ethically right? Was it even dentistry? It even prompted the Oral Health Foundation and the British Orthodontic Society to form a national campaign warning people about the dangers of DIY orthodontics.

Later that year, the General Dental Council accepted that remote orthodontic work falls within the practice of dentistry and noted reports of remote providers offering services without face-to-face patient contact with a dental registrant, a legal requirement under the Dentists Act 1984. The regulator emphasised that for all dental interventions 'this important interaction between clinician and patient should take place at the beginning of the patient consultation.' It was a step in the right direction, further bolstered last month when the regulator confirmed that direct-toconsumer orthodontic treatments using clear aligners fall within the legal definition of dentistry, meaning they can only be legally performed by a trained dental professional registered with the GDC. They also clarified that 'clinical judgements about the suitability of a proposed course of orthodontic treatment must be based on a full assessment of the

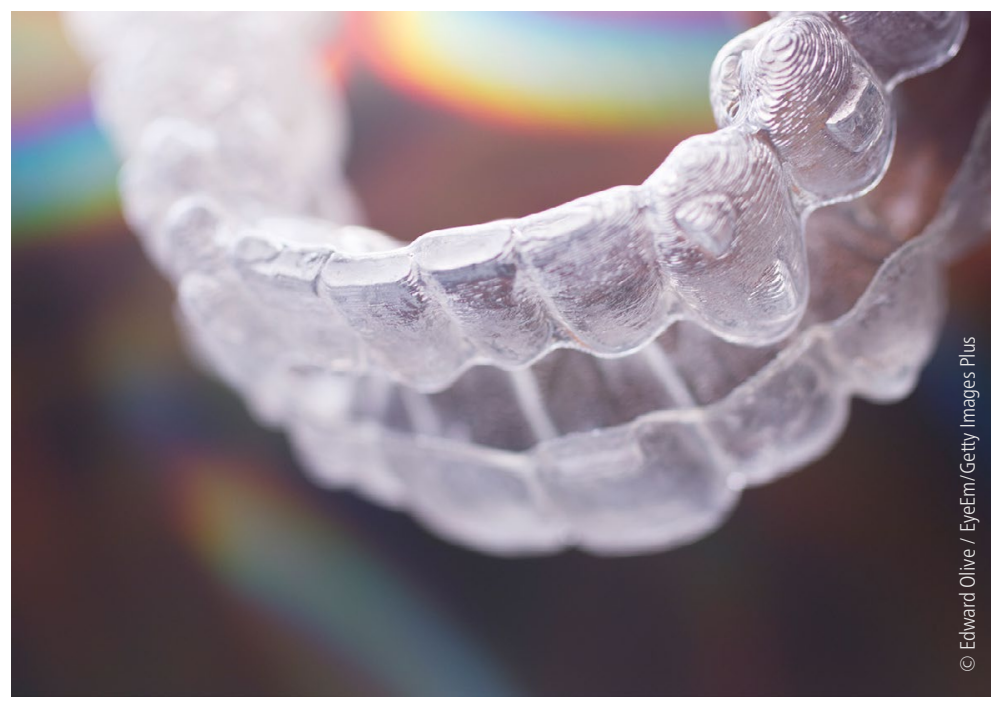
patient's oral health.'

The latest statement was widely welcomed, including by the Oral Health Foundation, the British Orthodontic Society and Henry Schein, who all supported the GDC's view that direct interaction between patient and practitioner is essential for safe and effective orthodontic procedures. Had the underlying cause of the itch finally been addressed, confining it to a problem of the past?

Not so fast, as the British Dental Association quite rightly pointed out that guidance for patients on the risks of direct-to-patient orthodontics is no substitute for meaningful regulation. They went on to add that the guidance does not offer any clarity on what sanctions the GDC might utilise and how the regulator backs up its assumption that such models of care are 'safe for many people' and now that remote procedures have been rightly defined as the 'practice of dentistry' by the GDC, at the bare minimum their premises need to be registered and inspected by the CQC in the same manner as other healthcare providers to ensure patient safety.

BDA Chair Eddie Crouch said it best guidelines are one thing, but what's really needed are rules and regulation to protect patients. What exactly has the regulator clarified - something we've already known? Not exactly ground-breaking, nor something that patients who have had to seek corrective treatment in the intervening months would deem acceptable. While they suspected that itching wouldn't make the problem go away, they fell short in applying moisturiser and instead kicked the issue down the road.

And so to today, where it is right that we ask why this remains as guidance (something you shouldn't do) rather than regulation (something you cannot do). For a profession - and regulator - that prides itself on patient safety, the continued lack of clarity is perplexing. Patients are warned not to scratch the direct-to-consumer orthodontic itch, but neither are they given the adequate remedy to stop doing it in the first place. It may be that the regulatory horse has bolted and it is too late to close the gate. While a satisfactory resolution may be some way off, we can take some solace from the mere fact dentistry is moving in the right direction with this. In the meantime, the only clarity on show remains the colour of the orthodontics.

\section{References}

1. General Dental Council. News release: Providing dental care remotely. 24 February 2020. Available online at: www.gdc-uk.org/newsblogs/news/detail/2020/02/24/providingdental-care-remotely (Accessed May 2021).

2. General Dental Council. GDC Statement on 'direct-to-consumer' orthodontic treatment. Available online at: www.gdc-uk.org/ information-standards-guidance/standards and-guidance/gdc-guidance-for-dentalprofessionals/direct-to-consumer-orthodontics/ gdc-statement-on-direct-to-consumerorthodontic-treatment (Accessed May 2021).

https://doi.org/10.1038/s41404-021-0775-7 